\title{
Extending the Specificity of DRL 72-s Behavior for Screening Antidepressant-Like Effects of Glutamatergic Clinically Validated Anxiolytic or Antidepressant Drugs in Rats ${ }^{[\mathrm{S}}$
}

\author{
(1) Gerard J. Marek and Allyson A. Salek \\ Yale School of Medicine Department of Psychiatry, Ribicoff Research Facilities of the Connecticut Mental Health Center, New \\ Haven, Connecticut
}

Received November 19, 2019; accepted March 13, 2020

\begin{abstract}
Both an agonist and its associated prodrug for metabotropic glutamate $2 / 3\left(\mathrm{mGlu}_{2 / 3}\right)$ receptors demonstrated anxiolytic efficacy in large, randomized, multicenter, double-blind, placebocontrolled trials studying patients with generalized anxiety disorder (GAD). These $\mathrm{mGlu}_{2 / 3}$ receptor agonists produced robust preclinical anxiolytic-like effects in rodent models. Several different metabotropic glutamate ${ }_{2}$ receptor positive allosteric modulators have been found to produce antidepressant-like effects on several preclinical screening paradigms, including differential-reinforcement-of-low-rate 72-second (DRL 72-s) behavior [increased reinforcers, decreased response rate, and cohesive rightward shifts in inter-response time distributions]. Although $\mathrm{mGlu}_{2 / 3}$ receptor agonists have not been tested formally for therapeutic effects in treating patients with major depressive disorder, these compounds generally fail to exert antidepressant-like effects in preclinical screening paradigms and did not improve depressive symptoms in GAD trials. Thus, the present studies were designed to test the potential antidepressant-like effects of the $\mathrm{mGlu}_{2 / 3}$ receptor agonist 1S,2S,5R,6S-2-aminobicyclo[3.1.0]hexane-2,6-bicarboxylate monohydrate (LY354740) on the DRL 72-s schedule. LY354740 did not test similarly to clinically validated antidepressant drugs when administered alone or when coadministered with the selective serotonin reuptake inhibitor fluoxetine in rats. Another
\end{abstract}

glutamate-based antidepressant drug, the uncompetitive $\mathrm{N}$-methyl-D-aspartate channel blocker racemic ketamine, exerted antidepressant-like effects when administered at subanesthetic doses in rats. The findings further support the specificity of rat DRL 72-s behavior when screening for anxiolytic versus antidepressant drugs and extend testing of compounds with glutamatergic mechanisms of action.

\section{SIGNIFICANCE STATEMENT}

The metabotropic glutamate $2 / 3$ receptor agonist and clinically validated anxiolytic drug $1 S, 2 S, 5 R, 6 S-2$-aminobicyclo[3.1.0] hexane-2,6-bicarboxylate monohydrate did not test similar to antidepressant drugs (increased reinforcers, decreased response rate, and cohesive rightward shifts in the inter-response time distribution) when tested on differential-reinforcement-of-low-rate 72-second (DRL 72-s) behavior and also did not enhance the antidepressant-like effects of the serotonin reuptake inhibitor fluoxetine. The uncompetitive $N$-methyl-D-aspartate receptor antagonist ketamine increased the reinforcement rate, decreased the response rate, and induced a rightward shift in the interresponse time distribution similar to antidepressant drugs; these results confirm the utility of DRL 72-s schedule of reinforcement when testing clinically validated anxiolytic versus antidepressant glutamatergic drugs.

\section{Introduction}

Two important tasks for neuropsychiatric medicationscreening paradigms are to continue testing activity of therapeutic versus nontherapeutic drugs based on available clinical and preclinical data and to extend testing to novel mechanisms of action (MoAs), especially those MoAs that are

This work was supported by the National Institutes of Health (NIH) National Institute of Mental Health [Grants R01 MH-62186, NIH K08 MH01551] and the State of Connecticut.

https://doi.org/10.1124/jpet.119.264069.

S This article has supplemental material available at jpet.aspetjournals.org. not part of the initial generation(s) of therapeutic drugs. Almost all approved antidepressant drugs are based on monoaminergic MoA, thus compounds that modulate glutamate are an important discovery target to discover novel antidepressant drugs based on two features. First is the preponderance synapses releasing glutamate, and second is the involvement of glutamatergic receptors and transporters in synaptic plasticity. $1 S, 2 S, 5 \mathrm{R}, 6 S$-2-aminobicyclo[3.1.0] hexane-2,6-bicarboxylate monohydrate (LY354740) and the corresponding peptidyl prodrug (LY544344) are agonists or agonist prodrugs for metabotropic glutamate $2 / 3\left(\mathrm{mGlu}_{2 / 3}\right)$ receptors that exerted therapeutic effects in large, randomized,

ABBREVIATIONS: DRL, differential-reinforcement-of-low-rate; DRL 72-s, DRL 72-second; GAD, generalized anxiety disorder; 5-HT, 5hydroxytryptamine; IRT, inter-response time; LY354740, 1S,2S,5R,6S-2-aminobicyclo[3.1.0]hexane-2,6-bicarboxylate monohydrate; LY544344, LY354740 peptidyl prodrug; M100907, R-(+)- $\alpha$-(2,3-dimethoxyphenyl)-1-[2-(4-fluorophenyl)ethyl-4-piperidinemethanol]; MDD, major depressive disorder; $\mathrm{mGlu}_{2}$, metabotropic glutamate $\mathrm{mGlu}_{2 / 3}$, metabotropic glutamate $\mathrm{m}_{2 / 3} ; \mathrm{mGlu}_{3}$, metabotropic glutamate $\mathrm{m}_{3} ; \mathrm{MoA}$, mechanism of action; mPFC, medial prefrontal cortex; MW, molecular weight; NMDA, $N$-methyl-D-aspartate; PAM, positive allosteric modulator; REM, rapid eye movement; SSRI, serotonin selective reuptake inhibitor; veh, vehicle. 
multicenter, double-blind, placebo-controlled, positive, comparator-controlled, clinical research trials in patients with generalized anxiety disorder (GAD) (Michelson et al., 2005; Dunayevich et al., 2008). LY354740 and LY544344 demonstrated effects similar to those associated with Food and Drug Administration-approved anxiolytic medications when employing preclinical screens/models testing for anxiety-like behavior/physiology (Schoepp et al., 2003; Rorick-Kehn et al., 2006). The effects of $\mathrm{mGlu}_{2 / 3}$ receptor agonists in the elevated plus maze test appear to involve activation of $\mathrm{mGlu}_{2}$ and $\mathrm{mGlu}_{3}$ receptors (Linden et al., 2005). Given the prominent localization of $\mathrm{mGlu}_{2}$ receptors in presynaptic terminals/ axons throughout the forebrain, activation of inhibitory $\mathrm{mGlu}_{2}$ autoreceptors in the forebrain probably plays a key role in both the unique preclinical profile and the therapeutic effects of $\mathrm{mGlu}_{2 / 3}$ receptor agonists (Schoepp, 2001; Wright et al., 2013). A contributory role of $\mathrm{mGlu}_{3}$ receptors, especially at postsynaptic sites in neurons on glia cells and on the terminals of GABAergic neurons, may be important for effects of $\mathrm{mGlu}_{2 / 3}$ receptor agonists in preclinical anxiolytic screens.

Interestingly, $\mathrm{mGlu}_{2}$ receptor positive allosteric modulators (PAMs) appear to result in antidepressant-like effects in preclinical rodent behavioral screens, including the rat differential-reinforcement-of-low-rate (DRL) 72-second (DRL 72-s) schedule of operant responding, the rat dominant-submissive test, the mouse forced swim test, and suppression of rapid eye movement (REM) sleep (Nikiforuk et al., 2010; Fell et al., 2011). In contrast, $\mathrm{mGlu}_{2 / 3}$ receptor agonists have not been found to test similar to known antidepressant drugs on the mouse forced swim test or the tail suspension test or downregulate $\beta$-adrenergic receptors, although they do enhance certain biochemical effects of antidepressants or behavioral effects of antidepressants on the forced swim test in the Flinders-sensitive line rats (Kłodzińska et al., 1999; Matrisciano et al., 2005, 2007).

Another preclinical rationale to address potential antidepressant-like effects of $\mathrm{mGlu}_{2 / 3}$ agonists are analogous effects of adenosine $A_{1}$ receptor agonists. Adenosine $A_{1}$ receptor agonists play a robust role in suppressing glutamate release from many of the same forebrain synapses as do $\mathrm{mGlu}_{2}$ receptors (inhibitory presynaptic heteroreceptors vs. autoreceptors) as previously described (Dunwiddie and Masino, 2001). Furthermore, activation of adenosine $A_{1}$ heteroceptors suppress glutamate release (induced by $5-\mathrm{HT}_{2 \mathrm{~A}}$ receptor activation) onto layer $\mathrm{V}$ pyramidal neurons similar to $\mathrm{mGlu}_{2}$ autoreceptors (Marek et al., 2000; Stutzmann et al., 2001). Given the importance of layer V pyramidal neurons projecting to the midline and intralaminar thalamic nuclei, amygdala, brainstem (including monoaminergic nuclei), and spinal cord together with profound effects of serotonergic hallucinogenic drugs on consciousness, the assumption is that modulation of $5-\mathrm{HT}_{2 \mathrm{~A}}$-induced synaptic activity may be an important substrate for a range of disease states, such as mood disorders and psychosis (Marek and Aghajanian, 1998; Aghajanian, 2009). Adenosine $\mathrm{A}_{1}$ receptor agonists also possess antidepressantlike actions on DRL 72-s behavior [increased reinforcers, decreased response rate, and cohesive shifts the interresponse time (IRT) distribution] in the forced swim test, the tail suspension test, and the suppression of REM sleep (Schwierin et al., 1996; Kaster et al., 2004; Marek, 2012). These antidepressant-like effects of $\mathrm{mGlu}_{2}$ receptor PAMs and adenosine $A_{1}$ receptor agonists at face value would appear to predict that a $\mathrm{mGlu}_{2 / 3}$ receptor agonist might exert antidepressant-like effects on rats performing under DRL 72-s schedules of reinforcement.

Since $\mathrm{mGlu}_{2 / 3}$ receptor agonists have not been previously tested on the DRL 72-s schedule, we tested the same orthosteric $\mathrm{mGlu}_{2 / 3}$ receptor agonist (LY354740), which has been found in the clinic to exert an anxiolytic effect, in rats performing under a DRL 72-s schedule. Dose selection was guided by 1) the previous testing of LY354740 (intraperitoneal administration; rats) in preclinical anxiolytic screens and the potency and efficacy of LY354740 in suppressing behavioral/ physiologic effects of $5-\mathrm{HT}_{2 \mathrm{~A}}$ receptor activation (Table 1 ) and 2) the in vitro potency of LY354740 for $\mathrm{mGlu}_{2}$ receptors compared with the brain exposures after a $10-\mathrm{mg} / \mathrm{kg}$ i.p. LY354740 dose (Battaglia et al., 1997). Given the functional interactions in corticothalamic circuitry between $5-\mathrm{HT}_{2 \mathrm{~A}}$ and $\mathrm{mGlu}_{2}$ receptors on DOI-induced head twitches and DRL 72-s behavior (Gewirtz and Marek, 2000; Marek et al., 2000, 2001; Benneyworth et al., 2007), we also tested the effects of LY354740 alone and together with the serotonin selective reuptake inhibitor (SSRI) fluoxetine, since $5-\mathrm{HT}_{2 \mathrm{~A}}$ receptor antagonists enhance the antidepressant-like effects of fluoxetine or the tricyclic antidepressant desipramine (Marek et al., 2005; Ardayfio et al., 2008). These positive preclinical effects of $5-\mathrm{HT}_{2 \mathrm{~A}}$ receptor antagonists and SSRIs have recently been translated to treatment-refractory patients with MDD (Fava et al., 2019). LY354740 failed to exert robust antidepressantlike effects when administered alone or even when administered in combination with selective serotonin reuptake inhibitor fluoxetine. In contrast, the uncompetitive NMDA receptor/channel blocker ketamine exerted antidepressantlike effects consistent with the clinical literature for both ketamine and esketamine (Berman et al., 2000; Niciu et al., 2014; Caddy et al., 2015; Daly et al., 2019; Fedgchin et al., 2019; Papova et al., 2019). These results with LY354740 and ketamine extend the specificity of the DRL 72-s schedule of reinforcement as a rodent model (O'Donnell et al., 2005; Marek et al., 2016) able to differentiate clinical anxiolytic versus antidepressant drugs while using these same clinically validated drugs to extend antidepressant drug screening with respect to the glutamatergic system. The broader significance of this work is described by recent reviews acknowledging that DRL behavior and the five-choice serial reaction time test both appear to involve motoric impulsivity based on cortico-thalamic-striatal macrocircuits (Dalley et al., 2011; Marek et al., 2016). Thus, compared with other behavioral antidepressant screens, DRL 72-s behavior appears to uniquely address impulsivity, executive function, and cognition. which are generally neglected domains for assessing the effects of novel antidepressant medications.

\section{Materials and Methods}

Animals. Forty male Sprague-Dawley rats weighing between 300 and $350 \mathrm{~g}$ at the beginning of the behavioral experiments (Holtzman, Madison, WI) were housed in suspended stainless steel wire cages (18 $\times 36 \times 20 \mathrm{~cm}$ ) with two rats per home cage. The colony room was kept at $20^{\circ} \mathrm{C}$ and $60 \%$ relative humidity. The room was illuminated 12 hours/day (07:00-19:00). The animals had free access to laboratory chow (Teklad 4\% Rat Diet) except during experimental sessions. Water was available for only a 20-minute period after the daily behavioral session. All animals were treated in accordance with the National Institutes of Health's Guide for the Care and Use of 
TABLE 1

Effects of LY354740 on rat DOI-induced or anxiety models

\begin{tabular}{|c|c|c|c|c|c|}
\hline $\begin{array}{l}\text { Behavioral or Physiologic } \\
\text { Test }\end{array}$ & $\begin{array}{l}\text { Doses Tested }(\mathrm{mg} / \mathrm{kg} \text {, } \\
\text { i.p., LY354740) }\end{array}$ & Observations Measured & $\begin{array}{l}\text { Minimal Effective Dose } \\
\text { (MED, mg/kg) of } \\
\text { LY354740 }\end{array}$ & $\begin{array}{l}\text { Maximal or Near } \\
\text { Maximal Effective } \\
\text { LY354740 Dose }\end{array}$ & References \\
\hline $\begin{array}{l}\text { DOI (1.25 mg/kg, i.p.)- } \\
\text { induced head } \\
\text { twitches }\end{array}$ & $0.3,1,3,10$ & $\begin{array}{l}\text { Suppression of DOI-induced head } \\
\text { twitches }\end{array}$ & 1 & 3 & $\begin{array}{l}\text { Gewirtz and } \\
\text { Marek, } 2000\end{array}$ \\
\hline $\begin{array}{l}\text { DOI ( } 5 \mathrm{mg} / \mathrm{kg}, \text { i.p. })- \\
\text { induced BDNF } \\
\text { mRNA }^{a}\end{array}$ & $0.1,1,10$ & $\begin{array}{l}\text { Suppression of DOI-induced increase } \\
\text { in BDNF mRNA (mPFC) }\end{array}$ & 1 & 10 & $\begin{array}{l}\text { Gewirtz et al., } \\
\quad 2002\end{array}$ \\
\hline $\begin{array}{l}\text { DOI ( } 3 \mathrm{mg} / \mathrm{kg} \text {, i.p.)- } \\
\text { induced c-fos } b\end{array}$ & $1,3,10$ & $\begin{array}{l}\text { Suppression of DOI-induced increase } \\
\text { in c-fos immunoreactivity (mPFC) }\end{array}$ & 3 & 3 & $\begin{array}{l}\text { Menezes et al., } \\
2013\end{array}$ \\
\hline $\begin{array}{l}\text { Vogel test or conflict } \\
\text { drinking test }\end{array}$ & $0.25,5,1,2,4$ & $\begin{array}{l}\text { Increase in punished responses while } \\
\text { drinking under threat of shock }\end{array}$ & 0.5 & 0.5 & $\begin{array}{l}\text { Kłodzińska } \\
\quad \text { et al., } 1999\end{array}$ \\
\hline $\begin{array}{l}\text { Lactate-induced panic } \\
\text { physiologic response }^{c}\end{array}$ & $0.3,0.6$ & $\begin{array}{l}\text { Suppression of lactate-induced } \\
\text { increases in cardio/respiratory } \\
\text { measures }\end{array}$ & 0.3 & 0.6 & $\begin{array}{l}\text { Shekhar and } \\
\text { Keim, } 2000\end{array}$ \\
\hline $\begin{array}{l}\text { Latate-induced panic } \\
\text { behavioral response }^{c}\end{array}$ & $0.3,0.6$ & $\begin{array}{l}\text { Attenuation of lactate-induced } \\
\text { decreases in social interaction }\end{array}$ & 0.6 & 0.6 & $\begin{array}{l}\text { Shekhar and } \\
\text { Keim, } 2000\end{array}$ \\
\hline Elevated plus maze $^{b}$ & $1,3,10$ & Increase in open arm time & 10 & 10 & $\begin{array}{l}\text { Ferris et al., } \\
2001\end{array}$ \\
\hline $\begin{array}{l}\text { Fear-potentiated } \\
\text { startle }^{b}\end{array}$ & $0.003,0.03,0.3,3$ & $\begin{array}{l}\text { Suppression of fear expression at } \\
\text { doses having no effects on fear } \\
\text { acquisition }\end{array}$ & 0.3 & 3 & $\begin{array}{l}\text { Tizzano et al., } \\
\quad 2002\end{array}$ \\
\hline
\end{tabular}

BDNF, brain-derived neurotrophic factor; MED, minimal effective dose.

${ }^{a}$ Fifteen-min LY354740 pretreatment before DOI administration and beginning of behavioral session.

${ }^{b}$ Thirty-min LY354740 pretreatment before DOI pretreatment and/or beginning of behavioral session.

${ }^{c}$ Sixty-min LY354740 pretreatment before beginning of behavioral session.

Laboratory Animals in use during the period in which the experimental studies were conducted. In addition, all protocols were approved by the Yale University Animal Care and Use Committee.

Apparatus. Eight MED Associates operant-conditioning chambers $(30.5 \times 24.1 \times 29.2 \mathrm{~cm}$; St. Albans, VT; www.med-associates.com $)$ were used for these behavioral experiments. The lever in these chambers was mounted on one wall with the water access next to the lever in the middle of the wall. A reinforced response caused the dipper (0.02-cc cup) to be lifted from a water trough to an opening in the floor of the access port for 4 seconds. The houselight (which was mounted on the opposite wall from the operant lever and water access port) was turned on when the session began, remained on during the entire session, and was turned off at the end of the session. Each experimental chamber was enclosed in a melamine sound-attenuating cubicle and equipped with a white noise generator that provided masking noise.

Operant Training. Rats were water-deprived for approximately 22.5 hours before each behavioral session. Each rat was initially trained under an alternative fixed ratio 1, fixed-time, 1-minute schedule for water reinforcement, meaning that each response was reinforced, and water also was provided every minute if a response did not occur. The occasional rats that did not acquire lever-pressing behavior after three daily 1-hour sessions under this schedule were trained by the experimenter using the method of successive approximation. After the rats had acquired lever-pressing behavior, they were trained during daily DRL 18-second sessions for about 2 weeks before moving directly to DRL 72-s sessions. The responding on these sessions became stable after about 8 weeks. Stable DRL 72-s schedule was defined as the S.E.M. Total response rate for each rat over five consecutive sessions was not greater than $10 \%$ of the corresponding mean. In addition, a goal for each cohort of trained rats was a mean reinforcement rate per hour of greater than 6 . Cohorts of rats trained with mean reinforcers per hour of fewer than 6 may have increased the reinforcement rate by a drug if that drug tended to produce a "random" IRT distribution, like benzodiazepines or $5-\mathrm{HT}_{1 \mathrm{~A}}$ receptor agonists. The duration of the experimental sessions was 1 hour, and these sessions were conducted 5 days/week during light hours at a consistent time of day for each cohort of rats.

Schedule Control and Statistical Analyses. The experimental chambers were connected to a personal computer via a MED-SYS-8 interface and software package. The number of reinforcers obtained and the total responses are shown in scatter plots that also display the mean \pm S.D. The DRL data analysis was performed on nontransformed data. The effects of LY354740 alone were analyzed with a one-factor repeated-measures ANOVA (GraphPad Prism 5; www. graphpad.com/scientific-software/prism). The effects of the combined treatment of LY354740 and fluoxetine were analyzed using a twofactor repeated-measures ANOVA, with LY354740 and fluoxetine as within-subject factors (Statistica 6.0; now owned by TIBCO Software Inc.). Significant main effects or interactions were further analyzed by the Newman-Keuls or Dunnett's test two-factor or one-factor ANOVAs per preplanned analyses. The level of significance was set for $P<0.05$ for all analyses. The cumulative IRT distribution for the entire group of rats treated with a within-subject design were analyzed with the nonparametric Kolmogorov-Smirnov (Statistica 6.0) test to make comparisons between different treatment conditions. This IRT analysis was conducted after placing individual IRT values into successive 6-second-duration bins for each individual rat. The last bin from 138.01 to 144 seconds also included all values greater than 144 seconds. A cumulative IRT distribution was then determined for the entire group for which the Kolmogorov-Smirnov test was made. Confirmatory sensitivity tests of IRT distributions at an individual animal level were also conducted and reported. The level of significance was set for $P<0.05$.

Drugs. Doses were calculated on the basis of the salt forms. All drugs were injected using a volume of $1 \mathrm{ml} / \mathrm{kg}$ body weight. LY354740 monohydrate (MW $=203.2 \mathrm{~g} / \mathrm{mol}$ ) was dissolved in saline and neutralized to $\mathrm{pH} 7$ with $5 \mathrm{~N} \mathrm{NaOH}$. The synthesis and structure of LY354740 were previously disclosed (Monn et al., 1997). Fluoxetine $\mathrm{HCl}(\mathrm{MW}=345.8 \mathrm{~g} / \mathrm{mol})$ was dissolved in $0.1 \%$ ascorbate in $0.9 \%$ saline. LY354740 and fluoxetine were generous gifts from Eli Lilly and company. Racemic ketamine $\mathrm{HCl}(\mathrm{MW}=274.2 \mathrm{~g} / \mathrm{mol}$ ) was also dissolved in saline. Ketamine was purchased from RBI (now SigmaAldrich RBI, Natick, MA). Drugs were administered to the animals only once weekly by an intraperitoneal route of administration prior to the behavioral session (Thursday) to minimize possible carryover effects. Ketamine, however, was injected only once every 2 weeks given the relatively long-lasting behavioral effects in patients compared with all other antidepressant medications. The behavior of each rat appeared to return to baseline the day after drug administration as established for rat DRL behavior. The pretreatment periods prior to 


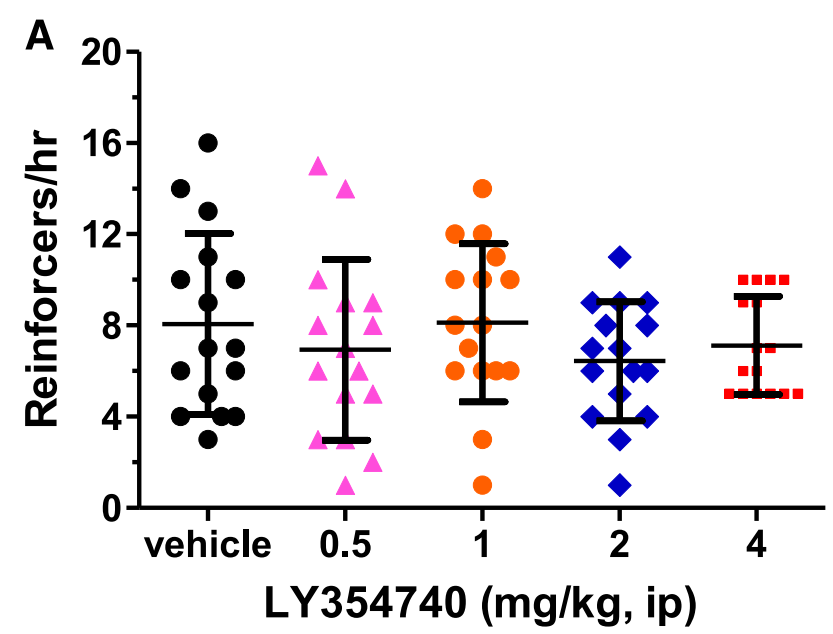

B
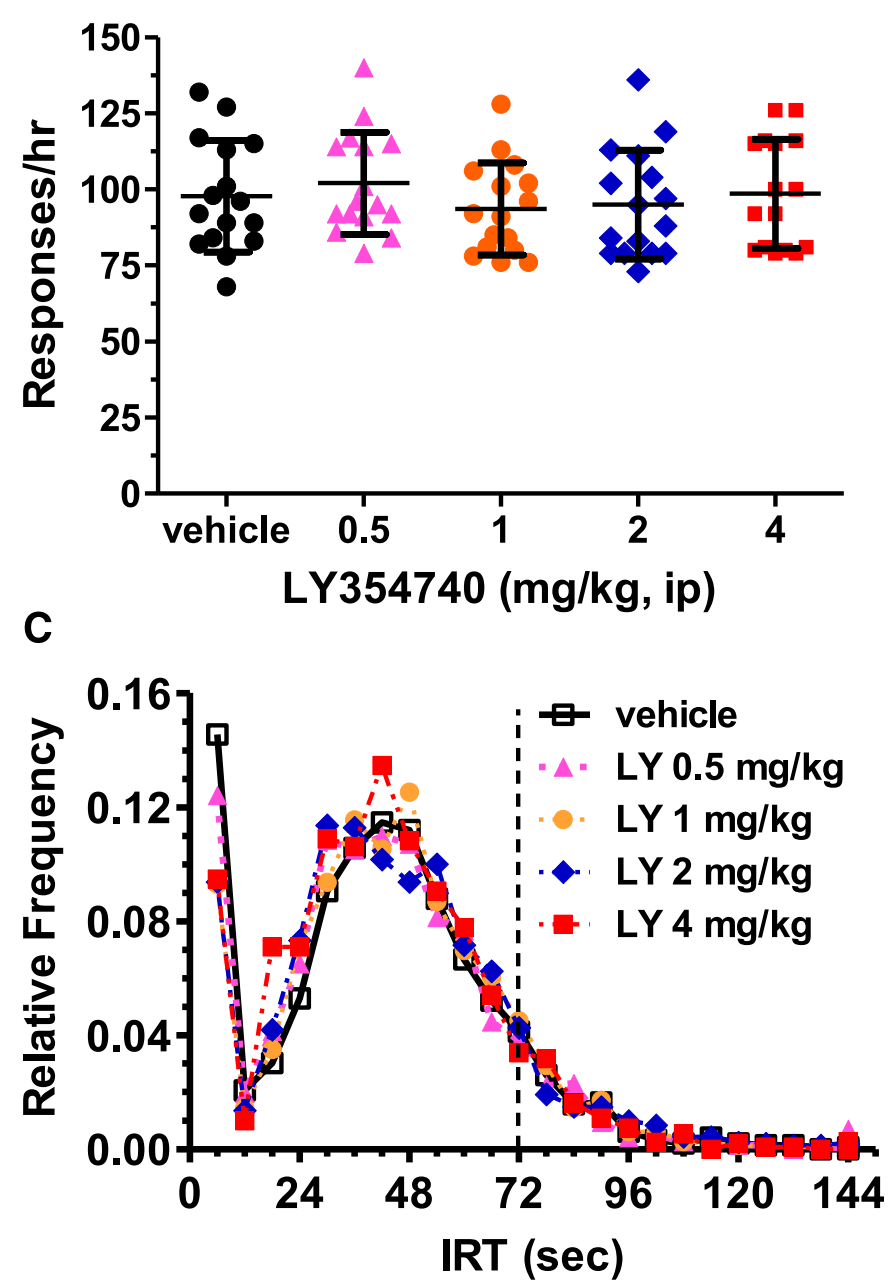

Fig. 1. Lack of appreciable effect of LY354740 on the number of reinforcers obtained (A), the number of total response (B), and the IRT distribution (C) for rats $(n=16)$ performing under a DRL 72-s schedule. Rats were injected with LY354740 (intraperitoneally) or vehicle 30 minutes prior to a 1-hour behavioral session. These results are the combined effects on two independent cohorts of eight rats because there did not appear to be appreciable differences between the two cohorts. The results (A and $\mathrm{B}$ ) are presented in the form of scatter plots in which the mean \pm S.D. are represented by the middle (mean) and the higher and the behavioral session for all experiments were 30 minutes for LY354740 and 1 hour for fluoxetine and ketamine.

\section{Results}

LY354740 Alone and DRL 72-s Behavior. The orthosteric $\mathrm{mGlu}_{2 / 3}$ receptor agonist LY354740 (0.5-4 mg/kg, i.p.) did not alter either the number of reinforcers $[\mathrm{F}(4,60)=1.47, P=0.22$; Fig. $1 \mathrm{~A}]$ or the number of total responses $[\mathrm{F}(4,60)=1.55, P=0.199$; Fig. 1B] obtained when using a 30-minute drug pretreatment for the hour-long behavioral session $(n=16)$. There also were no apparent dose-dependent shifts in the IRT distributions for the entire group of rats (Fig. 1C). At the lowest LY354740 dose, there was a very modest shift in the IRT distribution noted with the Kolmogorov-Smirnov test $[P<0.01$; IRTs (mean \pm S.D.) of $40.76 \pm$ 23.26 for vehicle and $38.54 \pm 23.43$ for $0.5 \mathrm{mg} / \mathrm{kg}$ LY354740]. The IRT distribution was not significantly different for LY354740 from the vehicle condition at any of the other $\operatorname{doses}(P>0.1)$. The results shown here are the combined results in two separate cohorts of eight rats since there were no differences between the groups after the administration of LY354740.

This lack of antidepressant-like effects on the IRT distribution at the group level was confirmed by analyzing shifts in the IRT distribution compared with vehicle for any dose in any of the 16 rats with the Kolmogorov-Smirnov test. There was a statistically significant shift in the IRT distribution associated with an increase in the mean IRT value for only 1 of 16 rats at multiple doses ( $P<0.01$ for the 1 and $4 \mathrm{mg} / \mathrm{kg}$ LY354740 dose). Only for the $1-\mathrm{mg} / \mathrm{kg}$ LY354740 dose did more than 2 of 16 rats (three) demonstrate a statistically significant shift in the IRT distribution associated with an increase in the mean IRT value $(P<0.01)$. Also, only for the $2-\mathrm{mg} / \mathrm{kg}$ LY354740 dose did more than 2 of 16 rats (three) demonstrate a decrease in the mean IRT value with a statistically significantly different distribution compared with the vehicle condition $(P<0.01)$. At the highest dose, the IRT distribution was significantly different from the vehicle distribution only for 1 of 16 rats (increased mean IRT value, $P<0.01$ ). Thus, there were not robust, dose-dependent changes in the IRT distribution for individual rats when comparing LY354740 versus vehicle data.

Given difficulty at interpreting negative data, the effects of $10 \mathrm{mg} / \mathrm{kg}$ LY354740 were studied in a third independent cohort of eight rats. Again, LY354740 1) did not increase the number of reinforcers obtained [Fig. $2 \mathrm{~A}$; $\mathrm{t}(7)=0.678, P=0.52$ ], 2) did not decrease the response rate [Fig. $2 \mathrm{~B} ; \mathrm{t}(7)=0.00$, $P=1.00], 3)$ and failed to induce a cohesive rightward shift in the IRT distribution (Fig. 2C). Overall, there was a lack of antidepressant-like effects on DRL 72-s behavior with 0.5-10 $\mathrm{mg} / \mathrm{kg}$ LY354740 for the number of reinforcers obtained, the total number of responses, and robust cohesive rightward shifts in the IRT distribution.

LY354740 Fails to Potentiate the Antidepressant-Like Action of Fluoxetine. Since the selective $5-\mathrm{HT}_{2 \mathrm{~A}}$ receptor antagonist M100907 previously was found to enhance the antidepressant-like action of a SSRI fluoxetine, a tricyclic

lower bars, respectively. The vehicle condition is shown by black circles, whereas the data for the different LY354740 (LY) doses are represented by $0.5 \mathrm{mg} / \mathrm{kg}$, magenta triangles; $1 \mathrm{mg} / \mathrm{kg}$, orange circles; $2 \mathrm{mg} / \mathrm{kg}$, blue diamonds; and $4 \mathrm{mg} / \mathrm{kg}$, red squares. These same symbols (other than a square symbol for vehicle) are also used for the IRT distribution in (C). 


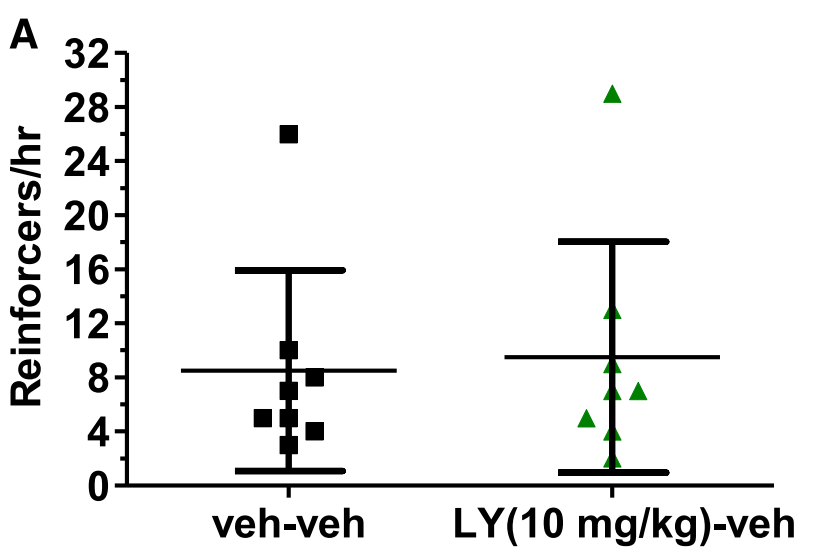

B

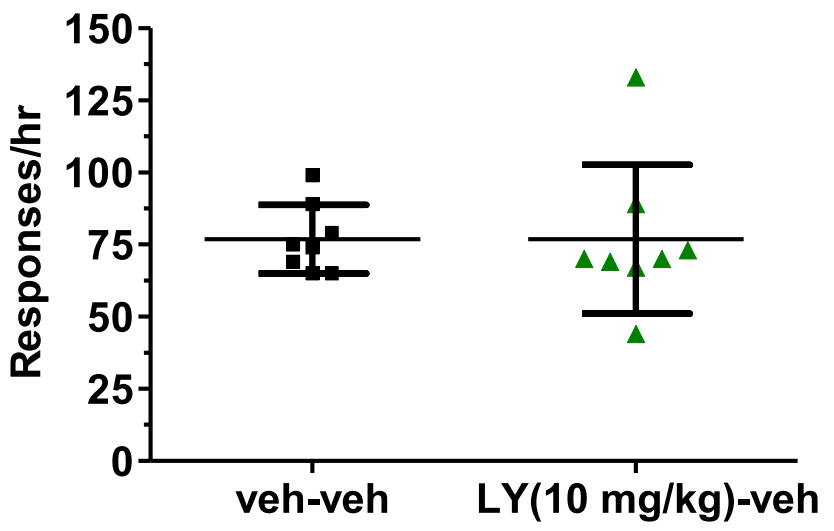

C

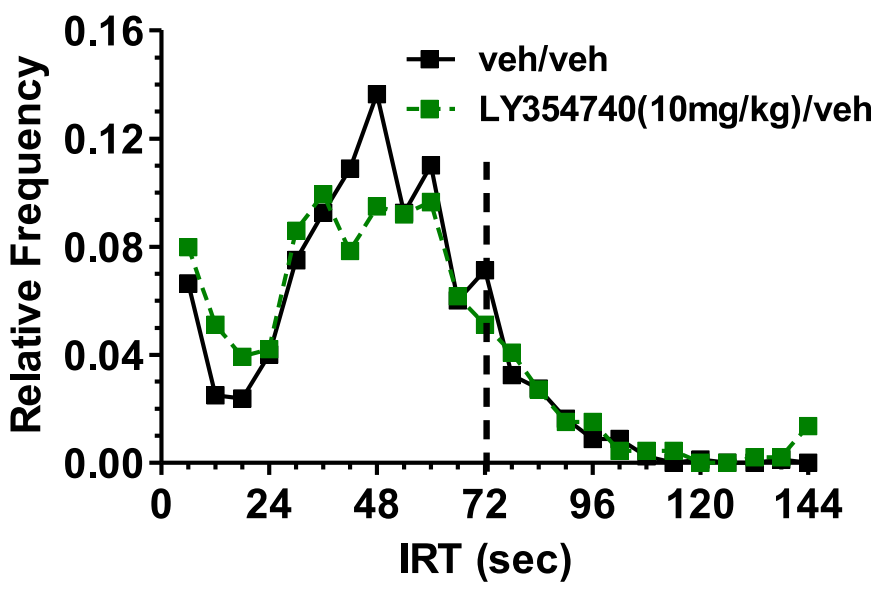

Fig. 2. Scatter plots showing that the highest dose of LY354740 (LY) (10 $\mathrm{mg} / \mathrm{kg}$, i.p.) administered 30 minutes prior to a 1-hour DRL 72-s session did not alter the number of reinforcers obtained (A) and total number of responses (B) and also did not induce a cohesive rightward shift in the IRT distribution. The mean + S.D. are presented for the vehicle and LY354740 treatment in (A and B). The cumulative group IRT distribution in which data were analyzed using successive 6-second bins is shown in (C). For each graph, the vehicle data are provided by black squares and LY354740 data are provided by green triangles.

antidepressant imipramine, and a monoamine oxidase inhibitor tranylcypromine and given the prominent electrophysiological, biochemical, and behavioral interactions between $5-\mathrm{HT}_{2 \mathrm{~A}}$ and $\mathrm{mGlu}_{2}$ receptors, the ability of the $\mathrm{mGlu}_{2 / 3}$ receptor agonist
LY354740 to potentiate the antidepressant-like action of fluoxetine was tested in a fourth cohort of eight rats. Fluoxetine (2.5-10 $\mathrm{mg} / \mathrm{kg}$, i.p.), as expected, did increase the number of reinforcers obtained [Fig. 3A; $\mathrm{F}(3,28)=7.54, P<0.001$ ], whereas there was no effect of LY354740 [4 mg/kg, i.p.; F(1, 28) $=0.87, P=0.359]$ nor an interaction between fluoxetine and LY354740 $[\mathrm{F}(3,28)=1.16, P=0.344]$ on this measure. Fluoxetine increased the number of reinforcers at the highest fluoxetine dose of $10 \mathrm{mg} / \mathrm{kg}$ either with saline or LY354740 cotreatment, approximately a doubling of reinforcers compared with vehicle-treated rats.

Fluoxetine (2.5-10 mg/kg, i.p.), also as expected, decreased the response rate [Fig. $3 \mathrm{~B} ; \mathrm{F}(3,28)=4.42, P<0.001$ ], whereas LY354740 (4 mg/kg, i.p.) did not alter the response rate $[\mathrm{F}(1$, $28)=0.54, P=0.47]$. There was a trend toward a statistically significant interaction of LY354740 and fluoxetine on the response rate $[\mathrm{F}(3,28)=2.57, P=0.075]$. However, post hoc testing demonstrated that the highest fluoxetine dose $(10 \mathrm{mg} / \mathrm{kg}$ ) decreased the response rate with vehicle and LY354740 cotreatment; the magnitude of the fluoxetineinduced decrease in response rate was approximately $30 \%$ and $18 \%$, respectively, for the vehicle versus LY354740treated conditions.

Fluoxetine exerted significant rightward shifts in the IRT distribution (Fig. 4) only for the $5 \mathrm{mg} / \mathrm{kg}$ condition $[P<0.001$; veh/veh $(42.52 \pm 22.01$ mean \pm S.D. $) ;$ veh/fluoxetine $(48.19 \pm$ 24.71)] and the $10 \mathrm{mg} / \mathrm{kg}$ treatment $[P<0.001$; veh/fluoxetine $(61.17 \pm 33.02)]$ but not the $2.5 \mathrm{mg} / \mathrm{kg}$ dose to the veh/veh condition $[P>0.1$; veh/fluoxetine (43.87 \pm 23.28)]. Like a previous experiment in a different cohort, there was not a significant change in the IRT distribution for $4 \mathrm{mg} / \mathrm{kg}$ LY354740 compared with the vehicle-vehicle condition (Fig. 4). However, there was a differential effect of LY354740 on the IRT distribution for the lowest compared with the highest dose. There was a significant rightward shift in the IRT distribution for the LY354740-2.5 $\mathrm{mg} / \mathrm{kg}$ fluoxetine combination compared with this dose of fluoxetine alone $[P<0.001 ;$ veh/fluoxetine 2.5 (43.87 \pm 23.28$) ;$ LY354740/ fluoxetine $2.5(47.19 \pm 26.71)]$. In contrast, there was a leftward shift in the IRT distribution for the LY354740-fluoxetine $10 \mathrm{mg} / \mathrm{kg}$ combination compared with this dose of fluoxetine alone $[P<0.001 ;$ veh/fluoxetine 10 (61.17 \pm 33.02$)$; LY354740/ fluoxetine $(51.53 \pm 33.20)]$.

Ketamine Exerts Antidepressant-Like Effect on DRL 72-s Behavior. The NMDA channel blocker ketamine (7.5-30 mg, i.p., 1 hour pretreatment) increased the number of reinforcers obtained [Fig. $5 \mathrm{~A} ; \mathrm{F}(3,18)=4.23, P<0.05]$ and decreased the response rate $[$ Fig. $5 \mathrm{~B} ; \mathrm{F}(3,21)=8.15, P<$ 0.001 ] with statistically significant changes only at the $30 \mathrm{mg} / \mathrm{kg}$ subanesthetic dose (Dunnett's test, $P<0.05$; Fig. 5). Ketamine (30 mg/kg) produced an $84 \%$ increase in the number of reinforcers while decreasing the response rate by approximately $30 \%$. The effects of ketamine on the IRT distribution were relatively modest (Fig. 5C). The primary effect was a flattening of the IRT response distribution with a broad plateau of IRTs from 42 to 84 seconds at the $30 \mathrm{mg} / \mathrm{kg}$ ketamine dose, although the distribution also appeared to be shifted rightward with the highest dose compared with the vehicle injection $[P<0.001$; IRTs (mean \pm S.D.) of $49.70 \pm$ 44.45 for vehicle and $68.27 \pm 88.17$ for $30 \mathrm{mg} / \mathrm{kg}$ ketamine]. This result at the group level of analysis was also observed when analyzing the effects of ketamine on the IRT distribution 


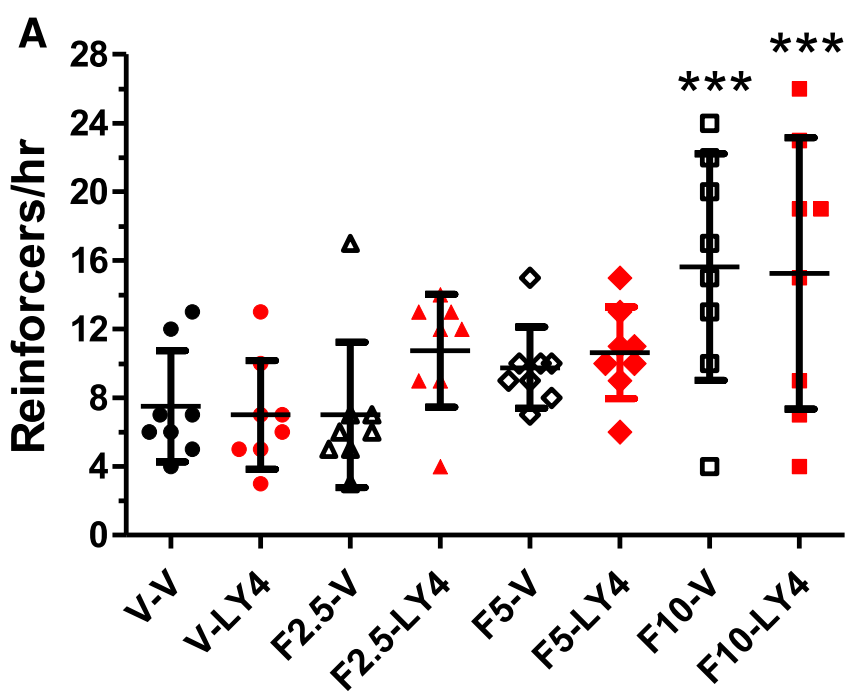

B

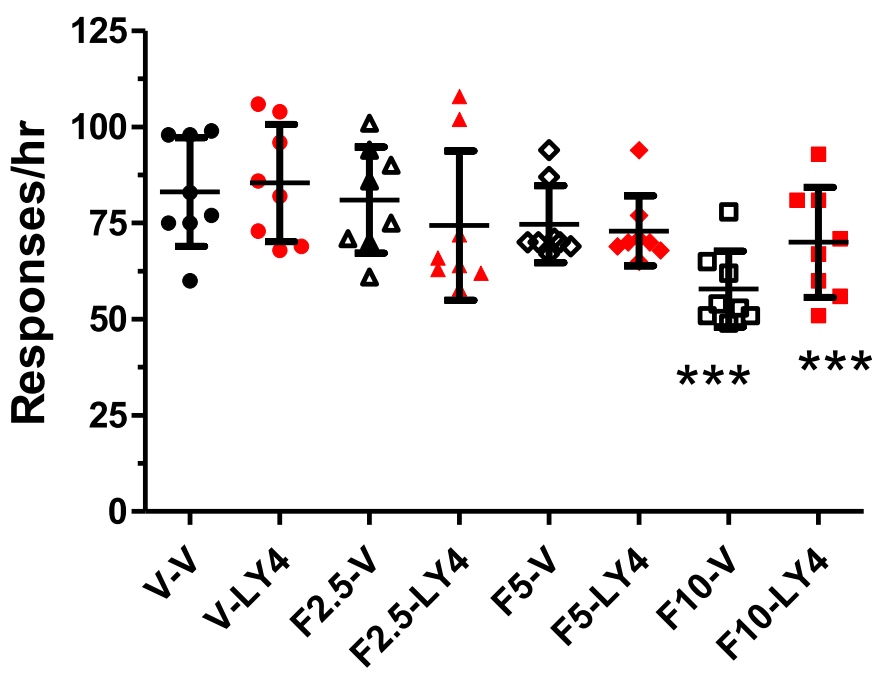

Fig. 3. LY354740 (4 mg/kg, i.p.) did not potentiate the reinforcement rate-increasing and response rate-decreasing effects of fluoxetine in rats $(n=8)$ performing under a DRL 72-s schedule. Rats were administered fluoxetine $(2.5-10 \mathrm{mg} / \mathrm{kg}$, i.p.) or vehicle 60 minutes prior to the hour-long behavioral session and were also injected with LY354740 or vehicle 30 minutes prior to the beginning of the 1-hour behavioral session. For the vehicle/vehicle condition, the mean ( \pm S.D. $)$ number of reinforcers obtained was $7.6( \pm 1.2)$, whereas the mean number of total responses was 88.4 $( \pm 5.0)$. For reinforcers obtained at the $10 \mathrm{mg} / \mathrm{kg}$ fluoxetine dose, both the fluoxetine alone condition and the fluoxetine/LY354740 condition were increased 2 -fold from vehicle conditions, ${ }^{* * *} P<0.001$. For total responses obtained at the $10-\mathrm{mg} / \mathrm{kg}$ fluoxetine dose, both the fluoxetine alone condition and the fluoxetine/LY354740 condition were decreased from vehicle conditions by $30 \%$ and $18 \%$, respectively, $* * * P<0.001$. F, fluoxetine; LY, LY354740; V, vehicle.

for individual rats. Five of seven rats showed a rightward shift in the IRT distribution for the $30 \mathrm{mg} / \mathrm{kg}$ ketamine dose $(P<$ $0.01)$ in those rats in which the response rate after ketamine was at least $30 \%$ of the response rate after vehicle treatment.

Given the relatively long-lasting effects of ketamine in the clinic of 1 to 2 weeks, post hoc exploratory analyses were conducted to determine whether persistent effects were present 1,2 , or 7 days after a single dose of the NMDA receptor antagonist. No significant effects were present for the 30-mg dose on any of these days (Fig. 6). The effects of the 7.5 and $15 \mathrm{mg} / \mathrm{kg}$ ketamine doses 1 hour after administration and at least 1 or 7 days after the single dose are shown in Supplemental Figs. 1 and 2.

\section{Discussion}

There are several implications of the present findings to understanding the specificity of the DRL 72-s schedule of reinforcements as a screen for detecting potential novel antidepressant drugs when considering screening validated anxiolytic versus antidepressant glutamatergic drugs. First, the orthosteric $\mathrm{mGlu}_{2 / 3}$ receptor agonist LY354740, which has been confirmed to produce anxiolytic effects in clinical studies and robust preclinical anxiolytic-like effects, failed to induce robust antidepressant-like effects when administered alone to rats performing under a DRL 72-s schedule, which has been validated as an antidepressant screen (O'Donnell et al., 2005). Thus, LY354740 did not 1) increase the number of reinforcers obtained, 2) decrease the total number of lever press responses,
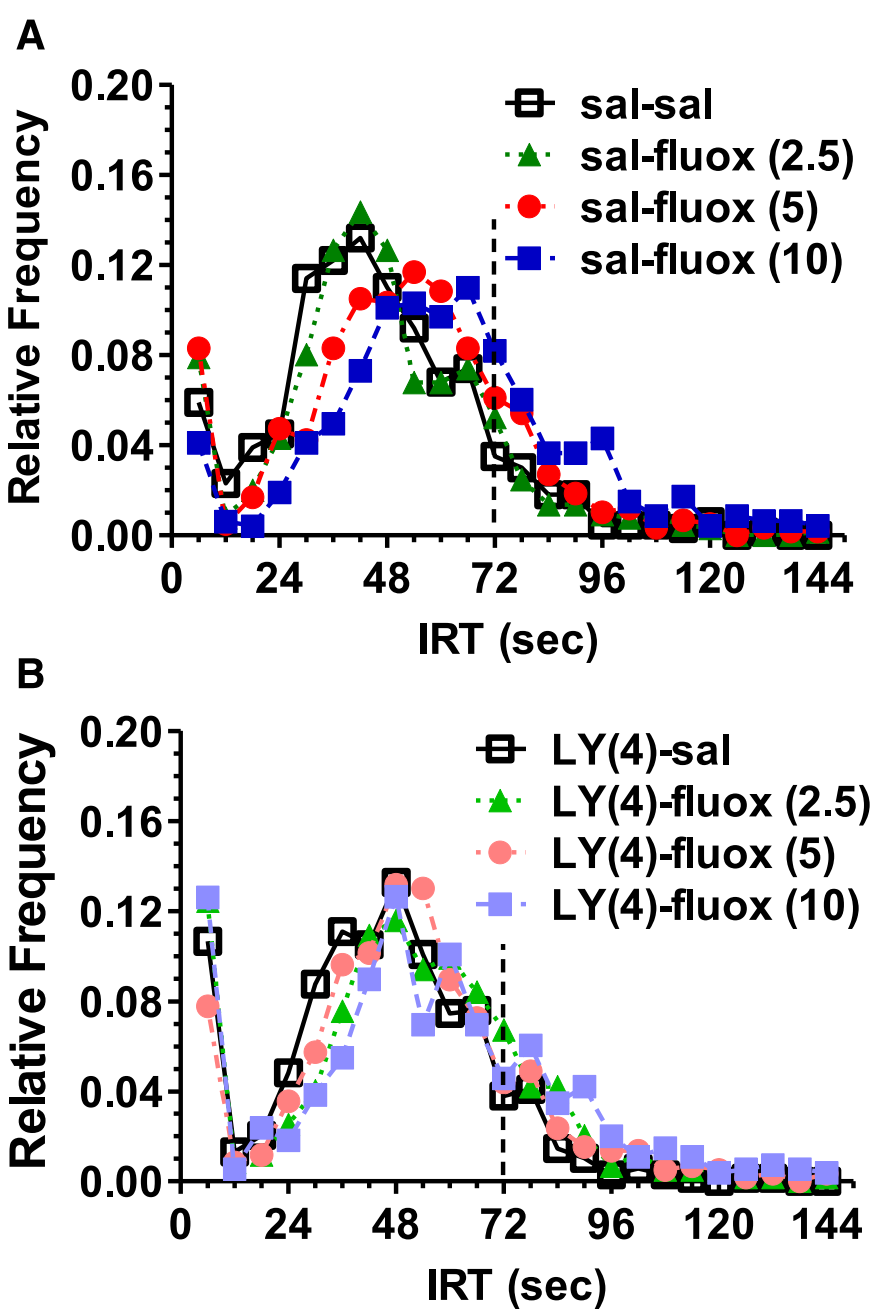

Fig. 4. LY354740 (4 mg/kg, i.p.) did not alter the IRT distribution induced by saline (sal) or fluoxetine (fluox) $(2.5-10 \mathrm{mg} / \mathrm{kg})$ in rats $(n=8)$ performing under a DRL 72-s schedule. The IRT distribution is in two panels displaying the effects of saline (open symbol) or fluoxetine, demonstrating a cohesive dose-related rightward shift induced by fluoxetine (A). The opposite rightward and leftward shift associated with LY354740 (LY) for the fluoxetine 2.5 - and $10-\mathrm{mg} / \mathrm{kg}$ doses, respectively, resulted in a blunting of the overall fluoxetine rightward shifts in the IRT distribution (B). 


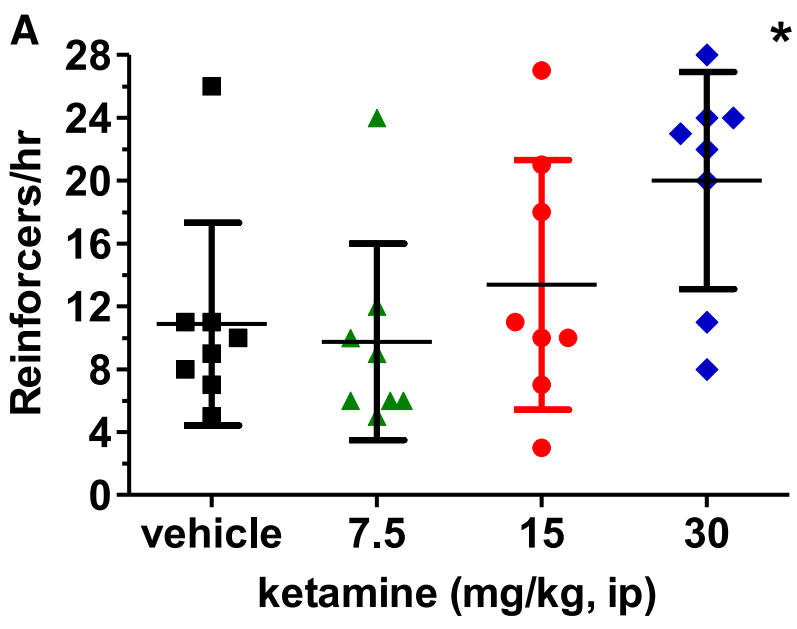

B

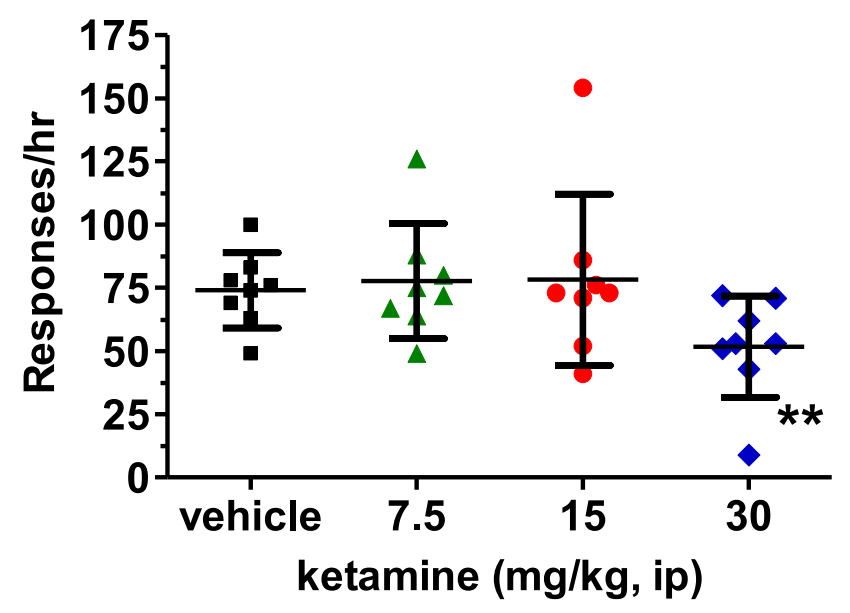

C

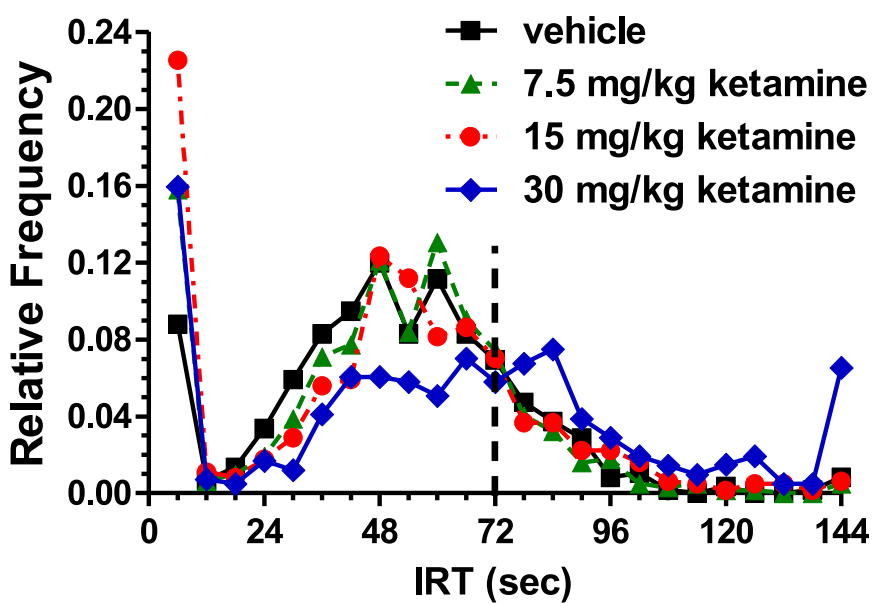

Fig. 5. Ketamine (7.5-30 mg/kg, i.p.) effects on DRL 72 -s behavior displayed by scatter plots and associated mean \pm S.D. bars. Ketamine increased the number of reinforcers obtained in a group of rats $(n=8)$, with a $84 \%$ increase at the $30-\mathrm{mg} / \mathrm{kg}$ dose [(A), $P<0.05]$. Ketamine also decreased the total responses made during the hour-long session by about $30 \%$ at the $30-\mathrm{mg} / \mathrm{kg}$ dose [(B) $* P<0.05]$. Vehicle is displayed as black squares, whereas ketamine is expressed by green triangles $(7.5 \mathrm{mg} / \mathrm{kg}$ ), red circles $(15 \mathrm{mg} / \mathrm{kg})$, and blue triangles $(30 \mathrm{mg} / \mathrm{kg})$. (C) displays the and 3) induce a cohesive rightward shift in the IRT distribution similar to most known antidepressant drugs. Furthermore, the $\mathrm{mGlu}_{2 / 3}$ receptor agonist failed to potentiate the antidepressant-like effects of the SSRI fluoxetine, unlike a previous study with the selective $5-\mathrm{HT}_{2 \mathrm{~A}}$ receptor antagonist M100907 (Marek et al., 2005). This failure to potentiate the antidepressant-like effects of the SSRI fluoxetine with LY354740 is surprising given functional interactions between prefrontal cortical $5-\mathrm{HT}_{2 \mathrm{~A}}$ and $\mathrm{mGlu}$ receptors (Marek et al., 2016) and the results of previous rat DRL 72-s experiments combining M100907 with the fluoxetine (Marek et al., 2005). The demonstrated antidepressant-like effects of fluoxetine in the LY354740/fluoxetine experiment serve as an internal positive control for the negative effects of LY354740 on DRL 72 -s behavior in this set of experiments. LY354740 exposures in the rat brain at the higher dose tested $(10 \mathrm{mg})$ are at least over 28-311-fold greater than the in vitro EC $_{50}$ of LY354740 at $\mathrm{mGlu}_{2}$ receptors (Battaglia et al., 1997). These LY354740 exposure multiples above the $\mathrm{EC}_{50}$ for $\mathrm{mGlu}_{2}$ receptors are also relevant for the $4 \mathrm{mg} / \mathrm{kg}$ dose in the fluoxetine study given linear pharmacokinetics for LY354740. Thus, this highly potent orthosteric $\mathrm{mGlu}_{2 / 3}$ receptor agonist does not appear to have antidepressant-like activity in rats performing under a DRL 72-s schedule from experiments in four independent rat cohorts, either when administered alone or when administered in combination with a known antidepressant drug.

A second important finding reported here with respect to the specificity of the DRL 72-s schedule as a preclinical antidepressant drug screen is the confirmation of antidepressantlike effects of the uncompetitive NMDA channel blocker ketamine (Hillhouse and Porter, 2014). These behavioral results in rats are consistent with the demonstrated antidepressant efficacy of ketamine or esketamine in patients with major depressive disorder (Berman et al., 2000; Caddy et al., 2015; Daly et al., 2019; Fedgchin et al., 2019; Popova et al., 2019). Ketamine produced characteristic changes on the reinforcement and response rate of rats performing on the DRL 72-s schedule similar to most known antidepressant drugs when administered 1 hour prior to the beginning of the behavioral session, a time point by which psychotomimetic effects of ketamine have largely subsided. Although the effects of single doses of ketamine in the clinic may result in antidepressant effects lasting up to 7-10 days, the effects on ketamine on DRL 72-s behavior in rats do not appear to be persistent and are only present on the day that they are administered. The present preclinical ketamine results on DRL 72-s behavior are in agreement with other preclinical predictions (forced swim test, tail suspension test, olfactory bulbectomy) for clinical antidepressant activity (Supplemental Table 1; Table 2).

From a predictive validity standpoint, these results appear in agreement with findings that most nonantidepressant

effects of vehicle or ketamine on the cumulative IRT distribution using symbols for the respective treatments as defined for (A) and (C). Although the 7.5- and $15-\mathrm{mg} / \mathrm{kg}$ dose conditions largely were without effect on the IRT distribution, for the highest tested subanesthetic dose of $30 \mathrm{mg} / \mathrm{kg}$, the peak of responding in the 48-60-second range was blunted with a modest rightward shift so that the peak was now observed at the 84-90-second time bin. 


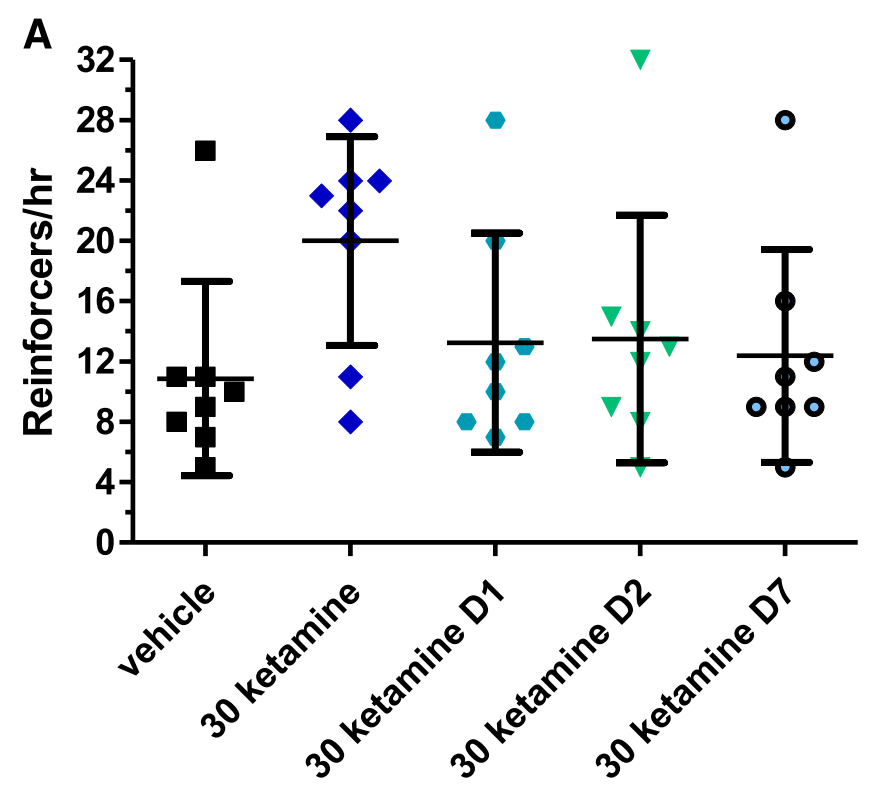

B

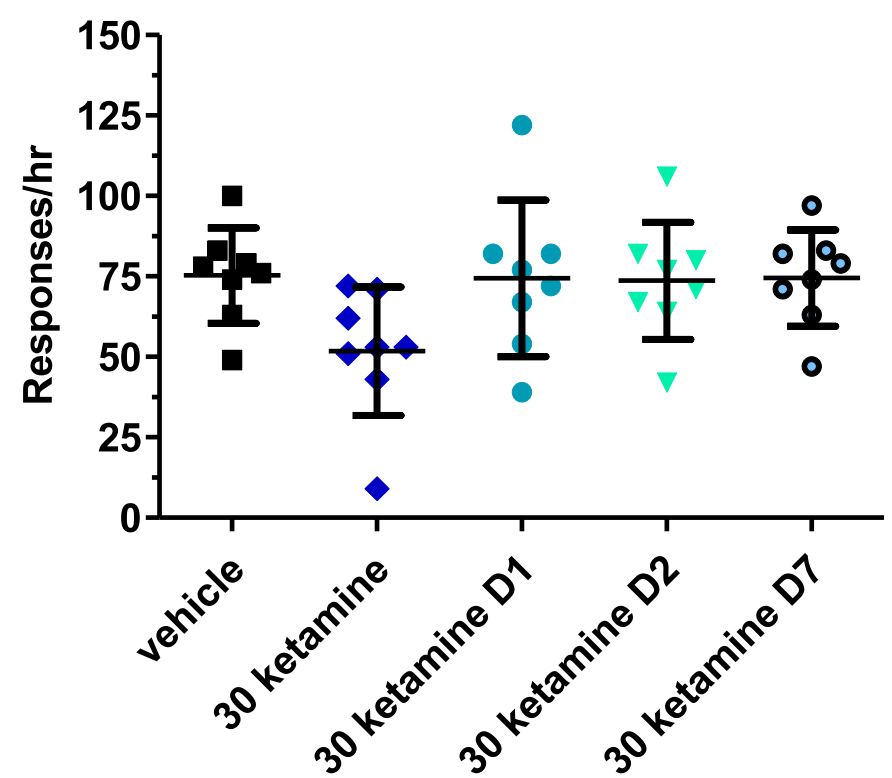

Fig. 6. Ketamine time course for $30-\mathrm{mg} / \mathrm{kg}$ dose compared with vehicle on DRL 72-s behavior. The "30 ketamine" label reflects the $30 \mathrm{mg} / \mathrm{kg}$ ketamine data shown in Fig. 5. The D1, D2, and D7 data refer to reinforcers and total responses made during the 60 -minute behavioral session 1, 2, and 7 days after the ketamine dose with the session conducted at the same time of day in each case. The same symbols are used for the vehicle and the effects of ketamine 60 minutes after injection as were used in Fig. 5. The DRL 72-s 1, 2, and 7 days after the $30-\mathrm{mg} / \mathrm{kg}$ ketamine injection are displayed by blue circles, blue-green inverted triangles, and blue circles with a black surrounding line, respectively.

drugs tested thus far do not increase the reinforcement rate, decrease the response rate, and induce cohesive rightward shifts in the IRT distribution similar to SSRIs, tricyclic antidepressants, norepinephrine reuptake inhibitors, monoamine oxidase inhibitors, heterocyclic antidepressants, and electroconvulsive shock (O’Donnell et al., 2005). LY354740 and the LY354740 prodrug, LY544344, attenuated anxiety symptoms from two different multicenter randomized placebo-controlled trials in patients with GAD (Michelson et al., 2005; Dunayevich et al., 2008). In these same GAD trials, LY354740 and LY544344 also failed to improve the modest comorbid depressive symptoms in subjects with GAD. These clinical results validated previous data suggesting LY354740 anxiolytic activity from experimental medicine studies in healthy volunteers or patients with panic disorder in addition to inferences from positive preclinical results in anxiety models (Table 2 ) with $\mathrm{mGlu}_{2 / 3}$ receptor agonists (Grillon et al., 2003; Schoepp et al., 2003; Kellner et al., 2005).

The lack of antidepressant-like activity for the orthosteric $\mathrm{mGlu}_{2 / 3}$ receptor agonist LY354740 across a range of rodent behavioral screens (including the rodent forced swim test and the tail suspension test; Supplemental Table 1; Table 2) is in agreement with the general failure to observe increases and decreases in the reinforcement and response rate and a cohesive rightward shift of the IRT distribution for well-known immediately acting anxiolytic medications, such as benzodiazepines (O’Donnell et al., 2005). Benzodiazepines are an example of medications approved for generalized anxiety disorder but not major depressive disorder.

Preclinical evidence supporting antidepressant-like activity of orthosteric $\mathrm{mGlu}_{2 / 3}$ receptor agonists has been at best quite limited compared with that of $\mathrm{mGlu}_{2 / 3}$ receptor antagonists (Supplemental Table 1; Table 2) (Witkin et al., 2007; Chaki, 2017). Negative results were obtained when testing LY354740 on other commonly used antidepressant drug screens, such as the forced swim test and the tail suspension test (Kłodzińska et al., 1999; Witkin et al., 2016, 2017) (Table 2). Outside of the suppression of REM sleep with $\mathrm{mGlu}_{2 / 3}$ receptor agonists or $\mathrm{mGlu}_{2}$ receptor PAMs (Feinberg et al., 2002; Ahnaou et al., 2009; Fell et al., 2011), the only other documented antidepressant-like effects of orthosteric $\mathrm{mGlu}_{2 / 3}$ receptor agonists are 1) the shortening of the temporal latency by which standard antidepressants reduce $\beta_{1}$-adrenergic receptor expression in the hippocampus and 2 ) reducing immobility time in the forced swim test in spontaneously depressed (Flinders-sensitive strain) rats (Matrisciano et al., 2005, 2007). The clinical significance of a compound speeding up the time course for downregulation of $\beta$-adrenergic receptors is unknown, especially for cases like the $\mathrm{mGlu}_{2 / 3}$ receptor agonists in which these drugs do not downregulate $\beta$-adrenergic receptors when administered alone.

Although the results of testing LY354740 on the rat DRL 72 -s schedule appear to be congruent with the known clinical actions of this drug as an anxiolytic drug lacking apparent antidepressant activity, the reason for the dissociation on DRL 72-s behavior between LY354740 on one hand and the preclinical antidepressant-like effects of $\mathrm{mGlu}_{2}$ receptor PAMs (Table 2) is not known. This dissociation could be due to an action of LY354740 at $\mathrm{mGlu}_{3}$ receptors that might functionally antagonize the effect of $\mathrm{mGlu}_{2}$ receptor activation. Alternatively, $\mathrm{mGlu}_{2}$ receptor PAMs may have a distinct neurochemical profile compared with $\mathrm{mGlu}_{2 / 3}$ receptor agonists, such as modulation of dopamine. The $\mathrm{mGlu}_{2}$ receptor PAM LY487389 did not increase extracellular levels of dopamine in the $\mathrm{mPFC}$, unlike increases in 5-HT and norepinephrine that were observed (Nikiforuk et al., 2010). In contrast, the orthosteric $\mathrm{mGlu}_{2 / 3}$ receptor agonist (-)-4-amino-2-oxabicyclo[3.1.0]hexane4,6-dicarboxylic acid has been shown to increase extracellular levels of dopamine in the mPFC while having some effect at also increasing 5-HT in this same region (Cartmell et al., 2000, 2001). These differences in dopamine levels in the neuropil may be 
TABLE 2

Effects of LY354740, $\mathrm{mGlu}_{2}$ receptor PAMs, $\mathrm{mGlu}_{2 / 3}$ receptor antagonists, and ketamine on MDD clinical trials, preclinical antidepressant screens, GAD clinical trials, and preclinical anxiolytic drug screens (see Supplemental Table 1 for this table with literature references)

\begin{tabular}{|c|c|c|c|c|}
\hline & LY354740 (mGlu ${ }_{2 / 3}$ Agonist) & mGlu $_{2}$ Receptor PAMs & $\mathrm{mGlu}_{2 / 3}$ Receptor Antagonists & Ketamine or Esketamine \\
\hline MDD clinical trials & not tested & Negative & Negative & POSITIVE \\
\hline DRL 72-s behavior & Negative & Positive & Negative & Positive \\
\hline Forced swim test & Negative & Positive & Positive & Positive \\
\hline Tail suspension test & Negative & not tested & Positive & Positive \\
\hline Olfactory bulbectomy & not tested & not tested & Positive & Positive \\
\hline GAD clinical trials & POSITIVE & not tested & not tested & not tested \\
\hline Elevated plus maze & Positive & Positive & Negative & Positive/negative \\
\hline Stress-induced hyperthermia & Positive & Positive & Positive/negative & not tested \\
\hline Lactate-induced panic & Positive & Positive & not tested & not tested \\
\hline Fear-potentiated startle & Positive & Positive & Positive/negative & Positive/negative \\
\hline
\end{tabular}

extremely important because a number of drugs blocking the dopamine transporter or increasing dopamine release (e.g., bupropion, nomifensine, methylphenidate, and amphetamine) tend to increase the response rate, decrease the reinforcement rate, and induce cohesive leftward shifts in the IRT distribution when administered to animals stably trained on the DRL 72-s schedule (O’Donnell et al., 2005).

As alluded to above, the present results with LY354740 appear to be validated with the known literature for testing of $\mathrm{mGlu}_{2 / 3}$ receptor antagonists on a range of behavioral antidepressant drug screens (Table 2). Although the $\mathrm{mGlu}_{2 / 3}$ receptor antagonist LY341495 did not posses antidepressant-like activity on the DRL 72-s schedule (Bespalov et al., 2008), different $\mathrm{mGlu}_{2 / 3}$ receptor antagonists exerted effects similar to known antidepressant drugs on the forced swim test, tail suspension test, and the olfactory bulbectomy model (Karasawa et al., 2005; Witkin and Eiler, 2006; Bespalov et al., 2008; PałuchaPoniewiera et al., 2010; Witkin et al., 2016). In addition, a dose of LY354740 (3 mg/kg) having no significant effects on forced swimming when administered alone did completely attenuate the antidepressant-like effects of a $\mathrm{mGlu}_{2 / 3}$ receptor antagonist (Witkin et al., 2017). Furthermore, similar antidepressant-like effects of both $\mathrm{mGlu}_{2 / 3}$ receptor antagonists and NMDA receptor antagonists on the forced swim test, tail suspension tests, and olfactory bulbectomy model appear to be mediated by known enhancement of glutamatergic transmission with activation of AMPA receptors in forebrain circuity (Table 2). This enhancement of glutamatergic transmission for $\mathrm{mGlu}_{2 / 3}$ receptors antagonists is exactly as predicted for an antagonist of $\mathrm{mGlu}_{2}$ autoreceptors in the forebrain and are contrasted with effects in the rat forebrain suggesting activation of $\mathrm{mGlu}_{2}$ autoreceptors by LY354740 and other $\mathrm{mGlu}_{2}$ receptor agonists (Schoepp, 2001).

A major limitation of the conclusions derived from the present results is that an orthosteric $\mathrm{mGlu}_{2 / 3}$ receptor agonist has not been adequately tested for antidepressant effects in patients with MDD. This limitation is partially mitigated by the fact that a range of screening paradigms for antidepressant drugs does not provide compelling evidence to advance LY354740 into a clinical antidepressant trial (see Table 2). Another mitigating factor is that depressive symptoms did not improve in GAD trials in which the $\mathrm{mGlu}_{2 / 3}$ receptor agonists did diminish symptoms of anxiety. The major strength of the present study is that the potential antidepressant effects of LY354740 were tested at exposures consistent with demonstrated significant anxiolytic efficacy in several randomized clinical trials for LY354740 or the LY354740 prodrug. A second strength of the present study, given a range of electrophysiological, biochemical, and behavioral interactions between $\mathrm{mGlu}_{2}$ and $5-\mathrm{HT}_{2 \mathrm{~A}}$ receptors (Marek, 2018), is that LY354740 doses/ exposures were tested that suppress the effects of $5-\mathrm{HT}_{2 \mathrm{~A}}$ receptor activation in the prefrontal cortex. Furthermore, fluoxetine was tested in a cohort of eight rats administered LY354740, and fluoxetine was shown to demonstrate an antidepressant-like effect either within the experiment or when subsequently tested in several of these groups.

In summary, the orthosteric $\mathrm{mGlu}_{2 / 3}$ receptor agonist LY354740 tested over a dose range shown to suppress the effects of hallucinogenic drugs activating $5-\mathrm{HT}_{2 \mathrm{~A}}$ receptors and demonstrating anxiolytic activity in a number of preclinical models failed to induce antidepressant-like activity in the DRL 72-s schedule. LY354740 is not known to possess antidepressant activity in the clinic but has demonstrated clinical anxiolytic activity. Given extensive overlapping biology between the $5-\mathrm{HT}_{2 \mathrm{~A}}$ and $\mathrm{mGlu}_{2}$ receptors in the prefrontal cortex and neocortex, the effects of LY354740 were also tested in combination with the SSRI fluoxetine, since the 5$\mathrm{HT}_{2 \mathrm{~A}}$ receptor antagonist M100907 enhances the antidepressant effects of fluoxetine, desipramine, and tranylcypromine (Marek et al., 2005; Ardayfio et al., 2008). However, LY354740 failed to significantly alter the antidepressant-like action of fluoxetine. In contrast to the lack of antidepressant-like effects of LY354740, the uncompetitive NMDA channel blocker ketamine did exert antidepressant-like effects on rats performing on the DRL 72-s schedule. These results add further weight to the working hypothesis that antidepressant drugs but not anxiolytic compounds without robust antidepressant action exert a characteristic profile of effects on the behavior of rodents performing under a DRL 72-s schedule (increased reinforcers, decreased response rate, and a cohesive rightward shift in temporal responding) (O'Donnell et al., 2005; Marek et al., 2016). Finally, these studies support the continued exploration of DRL 72-s behavior with novel compounds with primary MoA upon the glutamatergic system.

\section{Acknowledgments}

These experiments were performed in the Department of Psychiatry at the Yale University School of Medicine and the Ribicoff Research Facilities of the Connecticut. I thank Angela Keene, Andy Kwak, and Kim Reiss for technical assistance in carrying out the experiments.

\author{
Authorship Contributions \\ Participated in research design: Marek. \\ Conducted experiments: Marek, Salek. \\ Performed data analysis: Marek, Salek. \\ Wrote or contributed to the writing of the manuscript: Marek.
}




\section{References}

Aghajanian GK (2009) Modeling "psychosis" in vitro by inducing disordered neuronal network activity in cortical brain slices. Psychopharmacology (Berl) 206:575-585.

Ahnaou A, Dautzenberg FM, Geys H, Imogai H, Gibelin A, Moechars D, Steckler T, and Drinkenburg WH (2009) Modulation of group II metabotropic glutamate receptor (mGlu2) elicits common changes in rat and mice sleep-wake architecture. Eur J Pharmacol 603:62-72.

Ardayfio PA, Benvenga MJ, Chaney SF, Love PL, Catlow J, Swanson SP, and Marek GJ (2008) The 5-hydroxytryptamine2A receptor antagonist R-(+)-alpha-(2,3-dimethoxyphenyl)-1-[2-(4-fluorophenyl)ethyl-4-piperidinemethanol (M100907) attenuates impulsivity after both drug-induced disruption (dizocilpine) and enhancement (antidepressant drugs) of differential-reinforcement-of-low-rate 72 -s behavior in the rat. J Pharmacol Exp Ther 327:891-897.

Battaglia G, Monn JA, and Schoepp DD (1997) In vivo inhibition of veratridineevoked release of striatal excitatory amino acids by the group II metabotropic glutamate receptor agonist LY354740 in rats. Neurosci Lett 229:161-164.

Benneyworth MA, Xiang Z, Smith RL, Garcia EE, Conn PJ, and Sanders-Bush E (2007) A selective positive allosteric modulator of metabotropic glutamate receptor subtype 2 blocks a hallucinogenic drug model of psychosis. Mol Pharmacol 72: 477-484.

Berman RM, Cappiello A, Anand A, Oren DA, Heninger GR, Charney DS, and Krystal JH (2000) Antidepressant effects of ketamine in depressed patients. Biol Psychiatry 47:351-354.

Bespalov AY, van Gaalen MM, Sukhotina IA, Wicke K, Mezler M, Schoemaker H, and Gross G (2008) Behavioral characterization of the mGlu group II/III receptor antagonist, LY-341495, in animal models of anxiety and depression. Eur $J$ Pharmacol 592:96-102.

Caddy C, Amit BH, McCloud TL, Rendell JM, Furukawa TA, McShane R, Hawton K, and Cipriani A (2015) Ketamine and other glutamate receptor modulators for depression in adults. Cochrane Database Syst Rev:CD011612.

Cartmell J, Perry KW, Salhoff CR, Monn JA, and Schoepp DD (2000) The potent, selective mGlu2/3 receptor agonist LY379268 increases extracellular levels of dopamine, 3,4-dihydroxyphenylacetic acid, homovanillic acid, and 5-hydroxyindole-3acetic acid in the medial prefrontal cortex of the freely moving rat. J Neurochem $\mathbf{7 5}$ $1147-1154$

Cartmell J, Perry KW, Salhoff CR, Monn JA, and Schoepp DD (2001) Acute increase in monoamine release in the rat prefrontal cortex by the mGlu2/3 agonist LY379268 are similar in profile to risperidone, not locally mediated, and can be elicited in the presence of uptake blockade. Neuropharmacology 40:847-855.

Chaki S (2017) mGlu2/3 receptor antagonists as novel antidepressants. Trends Pharmacol Sci 38:569-580.

Dalley JW, Everitt BJ, and Robbins TW (2011) Impulsivity, compulsivity, and topdown cognitive control. Neuron 69:680-694.

Daly EJ, Trivedi MH, Janik A, Li H, Zhang Y, Li X, Lane R, Lim P, Duca AR, Hough D, et al. (2019) Efficacy of esketamine nasal spray plus oral antidepressant treatment for relapse prevention in patients with treatment-resistant depression: a randomized clinical trial. JAMA Psychiatry 76:893-903.

Delille HK, Becker JM, Burkhardt S, Bleher B, Terstappen GC, Schmidt M, Meyer AH, Unger L, Marek GJ, and Mezler M (2012) Heterocomplex formation of 5HT2A-mGlu2 and its relevance for cellular signaling cascades. Neuropharmacology 62:2184-2191.

Dunayevich E, Erickson J, Levine L, Landbloom R, Schoepp DD, and Tollefson GD (2008) Efficacy and tolerability of an mGlu2/3 agonist in the treatment of generalized anxiety disorder. Neuropsychopharmacology 33:1603-1610.

Dunwiddie TV and Masino SA (2001) The role and regulation of adenosine in the central nervous system. Annu Rev Neurosci 24:31-55.

Fava M, Dirks B, Freeman MP, Papakostas GI, Shelton RC, Thase ME, Trivedi MH, Liu K, and Stankovic S (2019) A phase 2, randomized, double-blind, placebocontrolled study of adjunctive pimavanserin in patients with major depressive disorder and an inadequate response to therapy (CLARITY). J Clin Psychiatry 80.

Fedgchin M, Trivedi MH, Daly EJ, Melkote R, Lane R, Lim P, Vitagliano D, Blier P, Fava M, Liebowitz M, et al. (2019) Efficacy and safety of fixed-dose esketamine nasal spray combined with a new oral antidepressant in treatment-resistant depression: results of a randomized, double-blind, active-controlled study (TRANSFORM-1). Int J Neuropsychopharmacol 22:616-630.

Feinberg I, Campbell IG, Schoepp DD, and Anderson K (2002) The selective group mGlu2/3 receptor agonist LY379268 suppresses REM sleep and fast EEG in the rat. Pharmacol Biochem Behav 73:467-474.

Fell MJ, Witkin JM, Falcone JF, Katner JS, Perry KW, Hart J, Rorick-Kehn L, Overshiner CD, Rasmussen K, Chaney SF, et al. (2011) N-(4-((2-(trifluoromethyl)3-hydroxy-4-(isobutyryl)phenoxy)methyl)benzyl)-1-methyl-1H-imidazole-4-carboxamide (THIIC), a novel metabotropic glutamate 2 potentiator with potential anxiolytic/ antidepressant properties: in vivo profiling suggests a link between behavioral and central nervous system neurochemical changes. J Pharmacol Exp Ther 336: $165-177$.

Ferris P, Seward E, and Dawson GR (2001) Interactions between LY354740, a group II metabotropic agonist and the GABA(A)-benzodiazepine receptor complex in the rat elevated plus-maze. J Psychopharmacol 15:76-82.

Gewirtz JC, Chen AC, Terwilliger R, Duman RC, and Marek GJ (2002) Modulation of DOI-induced increases in cortical BDNF expression by group II mGlu receptors. Pharmacol Biochem Behav 73:317-326.

Gewirtz JC and Marek GJ (2000) Behavioral evidence for interactions between a hallucinogenic drug and group II metabotropic glutamate receptors. Neuropsychopharmacology 23:569-576.

Grillon C, Cordova J, Levine LR, and Morgan CA III (2003) Anxiolytic effects of a novel group II metabotropic glutamate receptor agonist (LY354740) in the fearpotentiated startle paradigm in humans. Psychopharmacology (Berl) 168:446-454.

Hillhouse TM and Porter JH (2014) Ketamine, but not MK-801, produces antidepressant-like effects in rats responding on a differential-reinforcement-oflow-rate operant schedule. Behav Pharmacol 25:80-91.
Karasawa J, Shimazaki T, Kawashima N, and Chaki S (2005) AMPA receptor stimulation mediates the antidepressant-like effect of a group II metabotropic glutamate receptor antagonist. Brain Res 1042:92-98.

Kaster MP, Rosa AO, Rosso MM, Goulart EC, Santos ARS, and Rodrigues ALS (2004) Adenosine administration produces an antidepressant-like effect in mice: evidence for the involvement of A1 and A2A receptors. Neurosci Lett 355:21-24.

Kellner M, Muhtz C, Stark K, Yassouridis A, Arlt J, and Wiedemann K (2005) Effects of a metabotropic glutamate(2/3) receptor agonist (LY544344/LY354740) on panic anxiety induced by cholecystokinin tetrapeptide in healthy humans: preliminary results. Psychopharmacology (Berl) 179:310-315.

Kłodzińska A, Chojnacka-Wójcik E, Pałucha A, Brański P, Popik P, and Pilc A (1999) Potential anti-anxiety, anti-addictive effects of LY 354740 , a selective group II glutamate metabotropic receptors agonist in animal models. Neuropharmacology 38:1831-1839

Linden AM, Shannon H, Baez M, Yu JL, Koester A, and Schoepp DD (2005) Anxiolytic-like activity of the mGLU2/3 receptor agonist LY354740 in the elevated plus maze test is disrupted in metabotropic glutamate receptor 2 and 3 knock-out mice. Psychopharmacology (Berl) 179:284-291.

Marek GJ (2012) Activation of adenosine ${ }_{1}$ receptors induces antidepressant-like, anti-impulsive effects on differential reinforcement of low-rate 72 -s behavior in rats. J Pharmacol Exp Ther 341:564-570.

Marek GJ (2018) Interactions of hallucinogens with the glutamatergic system: permissive network effects mediated through cortical layer V pyramidal neurons. Curr Top Behav Neurosci 36:107-135.

Marek GJ and Aghajanian GK (1998) The electrophysiology of prefrontal serotonin systems: therapeutic implications for mood and psychosis. Biol Psychiatry 44: $1118-1127$.

Marek GJ, Day M, and Hudzik TJ (2016) The utility of impulsive bias and altered decision making as predictors of drug efficacy and target selection: rethinking behavioral screening for antidepressant drugs. J Pharmacol Exp Ther 356: 534-548.

Marek GJ, Martin-Ruiz R, Abo A, and Artigas F (2005) The selective 5- $\mathrm{HT}_{2 \mathrm{~A}}$ receptor antagonist M100907 enhances antidepressant-like behavioral effects of the SSRI fluoxetine. Neuropsychopharmacology 30:2205-2215.

Marek GJ, Wright RA, Gewirtz JC, and Schoepp DD (2001) A major role for thalamocortical afferents in serotonergic hallucinogen receptor function in the rat neocortex. Neuroscience 105:379-392.

Marek GJ, Wright RA, Schoepp DD, Monn JA, and Aghajanian GK (2000) Physiological antagonism between 5-hydroxytryptamine $(2 \mathrm{~A})$ and group II metabotropic glutamate receptors in prefrontal cortex. J Pharmacol Exp Ther 292:76-87.

Matrisciano F, Panaccione I, Zusso M, Giusti P, Tatarelli R, Iacovelli L, Mathé AA Gruber SH, Nicoletti F, and Girardi P (2007) Group-II metabotropic glutamate receptor ligands as adjunctive drugs in the treatment of depression: a new strategy to shorten the latency of antidepressant medication? Mol Psychiatry 12: 704-706.

Matrisciano F, Scaccianoce S, Del Bianco P, Panaccione I, Canudas AM, Battaglia G, Riozzi B, Ngomba RT, Molinaro G, Tatarelli R, et al. (2005) Metabotropic glutamate receptors and neuroadaptation to antidepressants: imipramine-induced down-regulation of beta-adrenergic receptors in mice treated with metabotropic glutamate 2/3 receptor ligands. J Neurochem 93:1345-1352.

Menezes MM, Santini MA, Benvenga MJ, Marek GJ, Merchant KM, Mikkelsen JD, and Svensson KA (2013) The mGlu2/3 receptor agonists LY354740 and LY379268 differentially regulate restraint-stress-induced expression of c-Fos in rat cerebral cortex. Neurosci $J$ 2013:736439.

Michelson D, Levine LR, Dellva MA, Mesters P, Schoepp DD, Dunayevich E, and Tollefson GD (2005) Clinical studies with mGlu2/3 receptor agonists: LY354740 compared with placebo in patients with generalized anxiety disorder. Neuropharmacology 49 (Suppl 1):257.

Monn JA, Valli MJ, Massey SM, Wright RA, Salhoff CR, Johnson BG, Howe T, Alt CA, Rhodes GA, Robey RL, et al. (1997) Design, synthesis, and pharmacological characterization of (+)-2-aminobicyclo[3.1.0]hexane-2,6-dicarboxylic acid (LY354740): a potent, selective, and orally active group 2 metabotropic glutamate receptor agonist possessing anticonvulsant and anxiolytic properties. J Med Chem 40:528-537.

Niciu MJ, Henter ID, Luckenbaugh DA, Zarate CA Jr, and Charney DS (2014) Glutamate receptor antagonists as fast-acting therapeutic alternatives for the treatment of depression: ketamine and other compounds. Annu Rev Pharmacol Toxicol 54:119-139.

Nikiforuk A, Popik P, Drescher KU, van Gaalen M, Relo A-L, Mezler M, Marek G, Schoemaker H, Gross G, and Bespalov A (2010) Effects of a positive allosteric modulator of group II metabotropic glutamate receptors, LY487379, on cognitive flexibility and impulsive-like responding in rats. $J$ Pharmacol Exp Ther 335: $665-673$

O'Donnell JM, Marek GJ, and Seiden LS (2005) Antidepressant effects assessed using behavior maintained under a differential-reinforcement-of-low-rate (DRL) operant schedule. Neurosci Biobehav Rev 29:785-798.

Pałucha-Poniewiera A, Wierońska JM, Brański P, Stachowicz K, Chaki S, and Pilc A (2010) On the mechanism of the antidepressant-like action of group II mGlu receptor antagonist, MGS0039. Psychopharmacology (Berl) 212:523-535

Popova V, Daly EJ, Trivedi M, Cooper K, Lane R, Lim P, Mazzucco C, Hough D, Thase ME, Shelton RC, et al. (2019) Efficacy and safety of flexibly dosed esketamine nasal spray combined with a newly initiated oral antidepressant in treatment-resistant depression: a randomized double-blind active-controlled study. Am J Psychiatry 176:428-438.

Rorick-Kehn LM, Perkins EJ, Knitowski KM, Hart JC, Johnson BG, Schoepp DD, and McKinzie DL (2006) Improved bioavailability of the mGlu2/3 receptor agonist LY354740 using a prodrug strategy: in vivo pharmacology of LY544344. J Pharmacol Exp Ther 316:905-913

Schoepp DD (2001) Unveiling the functions of presynaptic metabotropic glutamate receptors in the central nervous system. J Pharmacol Exp Ther 299:12-20. 
Schoepp DD, Wright RA, Levine LR, Gaydos B, and Potter WZ (2003) LY354740, an mGlu2/3 receptor agonist as a novel approach to treat anxiety/stress. Stress 6 189-197.

Schwierin B, Borbély AA, and Tobler I (1996) Effects of N6-cyclopentyladenosine and caffeine on sleep regulation in the rat. Eur J Pharmacol 300:163-171.

Shekhar A and Keim SR (2000) LY354740, a potent group II metabotropic glutamate receptor agonist prevents lactate-induced panic-like response in panic-prone rats. Neuropharmacology 39:1139-1146.

Stutzmann GE, Marek GJ, and Aghajanian GK (2001) Adenosine preferentially suppresses serotonin2A receptor-enhanced excitatory postsynaptic currents in layer V neurons of the rat medial prefrontal cortex. Neuroscience 105:55-69.

Tizzano JP, Griffey KI, and Schoepp DD (2002) The anxiolytic action of mGlu2/3 receptor agonist, LY354740, in the fear-potentiated startle model in rats is mechanistically distinct from diazepam. Pharmacol Biochem Behav 73:367-374.

Witkin JM and Eiler WJA (2006) Antagonism of metabotropic glutamate group I receptors in the potential treatment of neurological and neuropsychiatric disorders. Drug Dev Res 67:757-769.

Witkin JM, Marek GJ, Johnson BG, and Schoepp DD (2007) Metabotropic glutamate receptors in the control of mood disorders. CNS Neurol Disord Drug Targets 6 87-100.
Witkin JM, Mitchell SN, Wafford KA, Carter G, Gilmour G, Li J, Eastwood BJ, Overshiner C, Li X, Rorick-Kehn L, et al. (2017) Comparative effects of LY3020371, a potent and selective metabotropic glutamate (mGlu) $2 / 3$ receptor antagonist, and ketamine, a noncompetitive N-methyl-D-Aspartate receptor antagonist in rodents: evidence supporting the use of mGlu2/3 antagonists, for the treatment of depression. J Pharmacol Exp Ther 361:68-86.

Witkin JM, Monn JA, Schoepp DD, Li X, Overshiner C, Mitchell SN, Carter G, Johnson B, Rasmussen K, and Rorick-Kehn LM (2016) The rapidly acting antidepressant ketamine and the mGlu2/3 receptor antagonist LY341495 rapidly engage dopaminergic mood circuits. J Pharmacol Exp Ther 358:71-82.

Wright RA, Johnson BG, Zhang C, Salhoff C, Kingston AE, Calligaro DO, Monn JA, Schoepp DD, and Marek GJ (2013) CNS distribution of metabotropic glutamate 2 and 3 receptors: transgenic mice and $\left[{ }^{3} \mathrm{H}\right] \mathrm{LY} 459477$ autoradiography. Neuropharmacology 66:89-98.

Address correspondence to: Gerard J. Marek, Astellas Pharma Global Development, Inc., Medical Science, Medical Specialties, 6N-203, 1 Astellas Way, Northbrook, IL 60062. E-mail: gerard.marek@astellas.com 